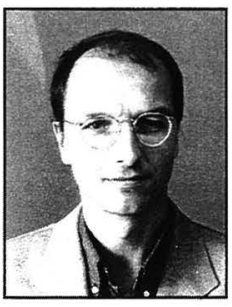

\title{
THE ECONOMIC PROGRESS OF MAORI MEN 1986-1996
}

\author{
Rainer Winkelmann \\ University of Canterbury, and Center for \\ Economic Policy Research, London
}

\begin{abstract}
Data for the Census years 1986, 1991 and 1996 show that Maori/non-Maori differences in employment and unemployment rates increased over the ten-year period. In search for a possible explanation, multinomial logit models are estimated with unit record data in order to control for changes in socio-economic and demographic factors such as age, qualification, and family and parental situation. The analysis shows that the Maori/non-Maori differences in employment (unemployment) that are explained by the multinomial logit models decreased from $51 \%(43 \%)$ in 1986 to $38 \%(34 \%)$ in 1996. Two potential contributors for declining relative labour market outcomes of Maori men are identified: increasing returns to skills and changes in the sectoral composition of the workforce.
\end{abstract}

Keywords: labour force status, multinomial logit, census data

The increasing disparities between Maori and non-Maori in Iabour market outcomes such as wages or employment rates in the second half of the 1980's are well documented. This trend is evident in statistics from the Household Labour Force Survey (that provides quarterly data from December 1985) as well as from Census data (using the years 1986 and 1991 as reference points). Very little, if any, of the increased disparities can be explained by changes between the Maori and non-Maori populations in relative supply side characteristics that are known to be correlated with labour market outcomes (See, for instance, Winkelmann and Winkelmann, 1997).

In this paper, I make use of data for the 1996 Census year in order to provide an updated analysis of the relative economic progress of Maori and non-Maori over the decade 1986-1996. Two independent observations make this a potentially very interesting question. First, the ten-year period comprises roughly a full business cycle, with 1986 and 1996 representing years of near full-employment and $1991 / 1992$ the trough of a recession. Hence, while it is beyond dispute that disparities were increasing between 1986 and 1991, the question then becomes whether the following recovery had also a disproportionately positive effect on Maori employment, bringing Maori in 1996 possibly back to a similar relative position as they had been in a decade earlier. If Maori/non-Maori disparities in Iabour market outcomes were mainly cyclical rather than structural, important consequences for policy would follow.

A second reason why an analysis of the economic progress of Maori between 1986 and 1996 is interesting is that half way through this ten-year period, in May 1991, the New Zealand system of industrial relations underwent substan- tial change. The Employment Contracts Act (ECA) replaced a system of centralised bargaining and compulsory union membership with a system of decentralised enterprise bargaining and free choice of bargaining agents (Harbridge, 1993). The economic consequences of this legislation are a topic of ongoing academic research. For instance Evans, Grimes and Wilkinson (1996) have shown that productivity growth was strong in the post-1991 period. Concurrently, employment grew substantially. Maloney (1997) estimates that at least 16 percent of the actual employment growth during the post-ECA period (up to 1996) can be attributed to the legislation. In a sense, the present paper provides an observation point on the potential consequences of the ECA, through its effects on the relative labour market opportunities for less skilled workers, for the relative economic progress of a minority group.

The analysis is based on unit record data from the 1986 , 1991 , and 1996 Censuses. The results are restricted to men for the sake of brevity. Economic progress is measured by labour force status - employment and unemployment - at Census day. ${ }^{1}$ In addition to reporting standard descriptive statistics, I estimate multinomial logit regression models of the determinants of labour force status. This type of analysis allows an interpretation of the labour market trends for Maori men relative to a well-defined benchmark, namely non-Maori men with similar productive and socio-economic characteristics.

The remainder of the paper is organised as follows. The next section describes the data set and summary statistics on employment rates of both Maori and non-Maori men. Subsequent text presents multinomial logit regression results in order to assess how (differences in) socio-economic 
characteristics determine (differences in) labour market outcomes. The section after that evaluates the structural change hypothesis, while conclusions and future research ideas end the paper.

\section{Data}

The data analysis in this paper is based on random samples from the New Zealand Population Censuses for 1986, 1991 and 1996. To be included in the sample in any of the three years a person had to be of working age (16-64 years old) with non-missing information on ethnicity in that year. For 1986 and 1991, 25,000 observations were drawn at random from each of the Maori and non-Maori populations. This constituted about $12 \%$ of all Maori and $1.5 \%$ of all non-Maori at the time (See Winkelmann and Winkelmann, 1997, for a more detailed description of the sampling). For the 1996 Census, the sampling strategy was different, as the sample now comprised a $5 \%$ sub-sample of the entire working age population. This sampling resulted in 15,231 Maori and 96,260 non-Maori observations. The differences in sampling should be immaterial to the validity of the comparisons, as sampling weights were applied whenever they were appropriate.

However, comparability of Maori characteristics and outcomes over time may be limited for a different reason, as (self-reported) ethnicity is an elusive concept. The measure is affected by social context and change, as well as by questionnaire design, for instance the treatment of multiple ethnicity. In 1996, over $15 \%$ of New Zealanders indicated that they belonged to more than one ethnic group. This was up from only 5\% in the 1991 Census and was partially caused by a rewording of the question (See also Chapple and Rea, 1999). The convention adopted in this analysis (and, for most purposes, by Statistics New Zealand) is a hierarchical definition. Everyone giving "Maori" as one of the cited ethnic groups is classified as Maori. Not surprisingly, the surge in multi-ethnicity led to a substantial increase in the proportion of Maori among all New Zealanders. In terms of the working age population, the proportion increased from $10.5 \%$ in 1986 and $11.1 \%$ in 1991 to $13.7 \%$ in 1996 .

One immediate consequence for the analysis of labour market outcomes is that computing employment growth rates can be misleading. In 1991, for example, an estimated 54,497 Maori men were in full-time employment. By 1996 full-time employment of Maori men had increased to 81,181 , an increase of 49 percent. During the same period and using the same type of calculation, non-Maori employment increased by only 13 percent. This comparison ignores that the composition of the population has shifted substantially, and Table 1 provides a more meaningful basis for a descriptive comparison using employment rates. Note that throughout this paper, employment rates are defined in proportion to the working age population rather than the labour force.

From Table 1, full-time employment rates increased between 1991 and 1996 by 2.8 percentage points for Maori, and by 0.9 percentage points for non-Maori. The increases in total employment rates, including part-time employment, were 7.3 and 4.5 percentage points, respectively. ${ }^{2}$ Hence, as in Evans et al. (1996), there is evidence that Maori employment rates increased substantially faster in the post1991 period than did non-Maori rates. This finding could indicate, among other things, that Maori employment rates were more sensitive to cyclical fluctuations than non-Maori rates, or that Maori men benefited disproportionally from the labour market deregulation of the early 1990's, or both.

In order to eliminate the effect of the recession, one possible approach is to compare the employment rates over a longer term, between 1986 and 1996 say. These two years were periods of near full-employment, in the sense that aggregate unemployment was close to its natural rate. Based on this comparison, Maori full-time employment rate fell by 18.5 percentage points, and the overall (full-time plus part-time) employment rate by 14.8 percentage points, over the ten-year period.

Concurrently, non-Maori employment rates fell by only 11.3 and 6.1 percentage points, respectively. Hence, the relative improvement in Maori employment rates between 1991 and 1996 was, by far, insufficient to compensate for the substantially larger previous relative losses between 1986 and 1991. Both Maori and non-Maori employment rates failed to return to their previous levels, but Maori were worse off relative to non-Maori in 1996 than they were in 1986. Similar conclusions can be reached with respect to unemployment rates.

How can we explain this development? From an economic point of view, it is useful to distinguish between supply and demand effects. On the supply side of the market, individual employment outcomes are determined by the characteristics of that person some of which, such as age and education, are observed by the analyst while others are

Table 1. Labour force status for Maori and non-Maori men in 1986, 1991 and 1996

\begin{tabular}{lrr}
\hline & Maori & non-Maori \\
\hline 1986 & & \\
Full-time employment & 0.718 & 0.820 \\
Part-time employment & 0.057 & 0.035 \\
Unemployment & 0.106 & 0.032 \\
Out of the labour force & 0.119 & 0.113
\end{tabular}

\section{1}

Full-time employment

0.505

Part-time employment

0.049

0.051

Unemployment

0.210

0.086

Out of the labour force

0.236

0.167

\section{6}

Full-time employment

Part-time employment

0.094

0.087

Unemployment

0.163

0.068

Out of the labour force
0.210 
unobserved, and by the value that the labour market puts on both observed and unobserved characteristics. In this framework, changes in the relative outcomes of two groups over time can be explained either by relative changes in the average characteristics of the two groups, or by changes in the market rewards to those characteristics. If, for instance, Maori have relatively lower levels of formal qualifications than non-Maori, and if market forces were to put over time a larger premium on those qualifications, then it follows that the relative position of Maori in the labour market can be expected to deteriorate, ceteris paribus.

On the demand side of the labour market, Maori outcomes may have been affected by sectoral change. If Maori and non-Maori were imperfect substitutes by virtue of their different levels of education and labour market experience and if employment opportunities disappeared in sectors where Maori were traditionally over-represented, then we would expect to see a decline in the relative outcomes of Maori, at least in the short-run, until further adjustments have taken place. The decline in employment could also indicate an increase in discrimination against Maori - again a change in demand conditions. In practice, it can be expected that both channels - supply and demand factors provide elements of an explanation. This paper studies the empirical evidence on each of the two.

\section{Changing characteristics and returns}

The labour supply based approach to differences in Maori and non-Maori labour market outcomes looks at the importance of factors such as age, education, and parental and marital status. Based on the human capital model, education and age can be seen as proxying market opportunities (e.g., persons with high human capital are more likely to be employed), whereas parental status is proxying the value of non-market activities (e.g., single parents have a relatively high value of non-market activities leading to lower employment rates). With respect to marital status, many studies have found that married men have a stronger labour market attachment and higher wages than unmarried men (e.g., because they traditionally are the main income provider).

As Table 2 shows, Maori men tended to have lower levels of formal qualifications, be younger, have a lower propensity of being married and a higher propensity of fatherhood, in particular as a single parent, than non-Maori men. Taking these factors as exogenously given, each of the four contributes a partial explanation of why Maori have lower employment and higher unemployment rates than nonMaori.

However, the empirical evidence in Table 2 does not support the hypothesis that the deterioration in the relative position of Maori men over time might have been caused by a deterioration in the relative characteristics. For instance, the relative endowments with qualifications remained largely unchanged between 1986 and 1996. For both Maori and non-Maori men, the proportion of working-age people with a post-secondary qualification hardly changed over the ten years (20 and 40 percent, respectively). An increase in the number of people with a university qualification came for both groups at the expense of a reduction of people with vocational qualifications. At the other end of the scale, the proportion of people without qualifications decreased over-proportionally for Maori. Hence, some convergence in characteristics occurred. Similarly, the relative age gap between Maori and non-Maori became somewhat smaller. A factor working "against" Maori men derives from the changing family variables, as the marital rates decreased, and the incidence of single parenthood increased, faster among Maori than among non-Maori men.

Of course, these factors are not independent (i.e., age, education and family status are correlated) and a regression analysis can be used to formally identify the joint contribution of all characteristics towards explaining the observed differences in outcomes, as well as the specific contribution of each factor. As the dependent variable "Labour Force Status" has four unordered nominal outcomes the multinomial logit model is an appropriate econometric approach. The adopted methodology is described in Winkelmann and Winkelmann (1997) where the interested reader can find more details. In general terms, the estimated coefficients of a multinomial logit model can be interpreted in terms of odds-ratios. While the full set of tables is available on request, I report here only certain quantities of interest that are derived from the estimated coefficients and discussed next.

For a start, Table 3 provides a decomposition of the Maori/ non-Maori employment and unemployment differentials into an explained part and an unexplained part. ${ }^{3}$ The basis

\section{Table 2. Sample averages of selected characteristics, 1986 and 1996}

\begin{tabular}{lcc}
\hline & Maori & non-Maori \\
\hline 1986 & & \\
No qualifications & 0.621 & 0.340 \\
School qualification & 0.183 & 0.252 \\
Vocational degree & 0.174 & 0.307 \\
University degree & 0.022 & 0.101 \\
Age & 31.1 & 36.3 \\
Married & 0.415 & 0.588 \\
Single parent & 0.022 & 0.010 \\
Joint parent & 0.385 & 0.365
\end{tabular}

\section{6}

No qualifications

0.506

0.273

School qualification

0.296

0.169

0.029

University degree

32.9

0.323

Age

0.328

0.124

Married

0.057

37.3

Single parent

0.353

0.522

Joint parent

0.015

0.368

Source: New Zealand Census, 1986 and 1996 
for this decomposition is the joint estimation of a model that postulates that Maori and non-Maori labour force status is equally affected by their respective characteristics. The estimated parameters are used to compute the average predicted probability of employment for Maori and nonMaori men separately and, from there, a predicted employment differential. The same is done for unemployment. This is very much in the spirit of a standard Oaxaca decomposition (Oaxaca, 1978), although the characteristics here are evaluated at the joint coefficients rather than at the Maori or non-Maori coefficients.

In this set-up the remaining unexplained differential has two possible interpretations. Either there are differences in Maori and non-Maori characteristics that affect labour force status but are unobserved by the researcher, or the coefficients differ between Maori and non-Maori, or both. Examples for the former include health (poorer Maori health could cause lower productivity and lesser attachment to the labour force), culture (Maori culture might reduce the labour force attachment by putting lower weight on material success and stressing communal values over individual ones) and discrimination. An example for the second factor is differences in school quality (the same formal qualification level increases Maori productivity by less than nonMaori productivity).

The numbers in the first two columns of Table 3 give the Maori minus the non-Maori probabilities. A positive (negative) number indicates that Maori (non-Maori) are more likely to be in that particular state in any given year. In 1986, Maori men had an 8 percentage points lower probability of employment than non-Maori. Based on differences in characteristics, we would have expected a differential of 4.1 percentage points. Hence about 51 percent the employment gap can be explained through differences in individual characteristics, while the rest is unexplained. In the same year, Maori men had a 7.4 percentage points higher probability of unemployment than non-Maori, 43 percent of which can be explained by differences in characteristics.

Between 1986 and 1996, two developments took place concurrently. First, the predicted Maori-non-Maori employment differential increased, from 4.1 percentage points to 6.4 percentage points. As we have learned from Table 2, there was no clear-cut increase in disparities by characteristics. Hence, it is more likely that the increased explained gap is caused by an increase in the coefficients of, or "returns" to, specific characteristics such as experience or qualifications that tended to put Maori men at an increasing disadvantage as they had relatively low levels of experience or qualifications.

The second development was that the overall employment gap increased substantially more than the predicted gap. As a consequence, the proportion of the employment gap that can be explained by the logit model fell from 51 percent in 1986 to 38 percent in 1996 . There are several possible explanations for this decline in the predictive power of the model. The first explanation is linked to the increased importance of factors that determine labour market outcomes but are unobserved by the econometrician (such as skill, effort, etc.). If either the distribution of these factors shifted between the two groups or the returns to unobservables increased the unexplained employment gap would tend to rise. An alternative explanation is that the response of labour market outcomes to observed characteristics differed between Maori and non-Maori, which would violate the assumption of common parameters underlying the decomposition in Table 3.

\section{Table 3. Decomposition of the difference in labour force status probabilities between Maori and non-Maori men, 1986 and 1996}

\begin{tabular}{lcll}
\hline & Actual & Explained & \% \\
\hline $\mathbf{1 9 8 6}$ & & & \\
Employment & -0.080 & -0.041 & 51 \\
Unemployment & 0.074 & 0.032 & 43 \\
1996 & & & \\
Employment & -0.167 & -0.064 & 38 \\
Unemployment & 0.095 & 0.032 & 34 \\
\hline
\end{tabular}

Source: New Zealand Census 1986 and 1996, own calculations.

To gain a better understanding of the latter issue separate models were estimated for Maori and for non-Maori. The next figures plot the average predicted employment probabilities for the four qualification levels for Maori and nonMaori men. The probability for non-qualified Maori men, for instance, is obtained by assigning the characteristic "no qualification" to all Maori in the sample, leaving their other characteristics as they were, and averaging over the predicted probabilities. Hence, this is our best estimate of what Maori employment would look like if all Maori were unqualified. ${ }^{4}$ The predicted probabilities for persons with school, vocational or university qualifications are computed in the same way.

In terms of substantive results, Figure 1 shows, somewhat surprisingly, that for 1986 employment rates were an inverse-U-shaped function of qualifications since a university degree did lead to lower predicted employment rate than a tertiary certificate from an institution other than university, both for Maori and for non-Maori. However, at the pre-tertiary level, there was a strong positive association between employment and qualifications. Figure 1 also shows that education was substantially more important for Maori than it was for non-Maori. For instance, Maori males with a tertiary certificate had an employment probability that was 15.4 percentage points above the rate for Maori males without a qualification. For non-Maori males, in contrast, the corresponding difference amounted to only 5.4 percentage points. Had all males in the sample obtained a tertiary certificate in 1986, predicted Maori employment would have been higher than predicted non-Maori employment. Overall, Maori and non-Maori employment rates were 
Figure 1. Predicted probability of employment by qualification, 1986

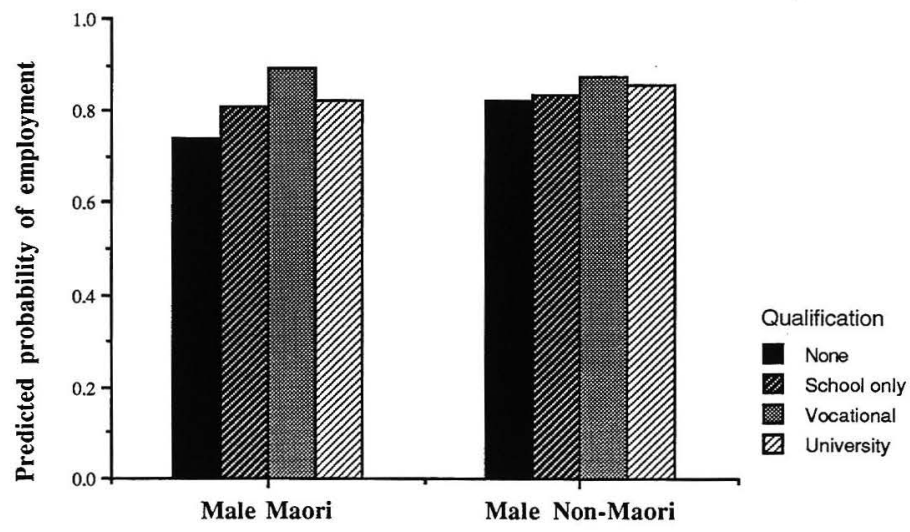

not that different, in particular for persons with at least a school qualification.

Figure 2 shows the corresponding graph for the 1996 data. Two differences relative to the graph for 1986 are noteworthy. First, while predicted employment was lower in 1996 than in 1986 for all qualification levels for both Maori and non-Maori, the decline was larger for Maori. As a con- sequence, Maori had, with the exception of university graduates, lower predicted employment rates than even nonMaori without any qualification. Second, the downward shift in levels was accompanied by an increase in the returns to qualifications. This increase, while observed for both groups, was substantially larger for Maori men, where the no-qualification-to-university employment gap increased to 23 percentage points, compared to 9 percentage

Figure 2. Predicted probability of employment by qualification, 1996

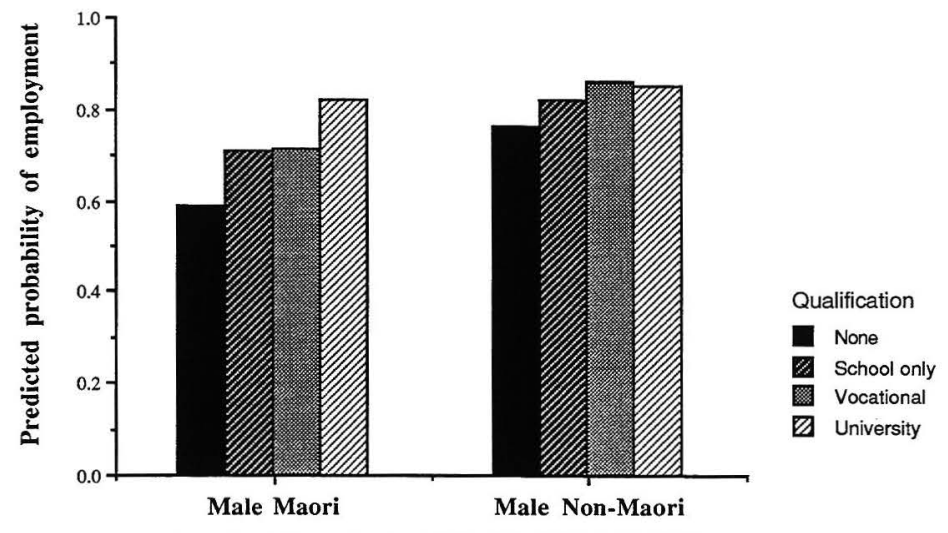


points for non-Maori men. The large differential effects of qualifications for Maori is an intriguing finding and it is not "good news", since it puts an exceptionally high penalty on having no qualification for this group.

In summary, I find that in terms of labour supply conditions, the overall employment gap between Maori and nonMaori increased from 1986 to 1996 due to two complementary reasons. First, the simple model predicted an increase in the observed gap, not so much because the distribution of observable characteristics became more dispersed but rather because of an increase in the rate of return to those characteristics. Second, employment rates for Maori men fell for reasons not captured by the model. While this development might have to do with unobserved supply side factors, a likely additional channel is through an interaction with demand side effects. In the next section, I investigate changes in the demand side of the labour market in order to explore the potential effects of sectoral change on the relative employment of Maori over the period.

\section{Sectoral change}

The sectoral change explanation for the increasing relative Maori/non-Maori disparities "blames" a concentration of Maori in certain industries and occupations. This is by no means a new explanation. Among others, Haines (1989) argued that Maori workers (and in particular Maori men) are concentrated in manual occupations in the primary and manufacturing industries where employment opportunities have been declining over the period, while Easton (1994, 1995) maintained that Maori are concentrated in a "secondary" labour market. I provide here additional evidence for this hypothesis by comparing the employment changes in a given industry over the ten-year period with the proportion of workers in that industry that were Maori in 1986.

Figure 3 shows that sectors in which Maori men were highly represented in 1986 tended to be sectors where total male employment would decrease over the next decade. ${ }^{5}$ Take for instance the Food industry. In 1986, 20 percent of all workers employed in that industry were Maori. Between 1986 and 1996 employment in that industry decreased by about 30 percent. At the other extreme were Business and Financial Services, where employment grew by 50 percent while Maori constituted only 4 percent of all workers in that industry in 1986.

This trend can be summarised as follows: overall male employment decreased by $7.7 \%$ between 1986 and 1996.6 If Maori employment had changed in all industries in proportion to the overall employment change in that industry, then the expected change in overall Maori employment, based on the initial industry distribution, would have been -13.7 percent, almost double the overall rate. Hence, Maori men were severely disadvantaged by the initial sectoral distribution of their employment.

There is, of course, no intrinsic reason why Maori men could not have moved to other sectors of the economy, and they did to some extent, as is apparent from Table 4. However, the adjustment was insufficient in order to overcome the strong pressures that were exerted by the sectoral change. Possibly, this process takes more time than allowed for by the horizon of this analysis.

Fig 3. Industry distribution and sectoral change 1986-1996.

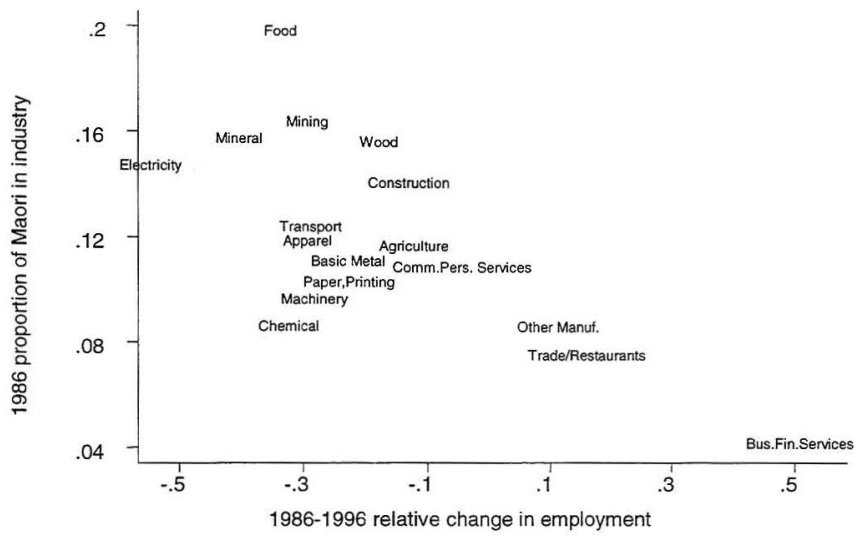




\section{Table 4. Industry distribution of employed Maori and non-Maori men, 1986 and 1996}

\begin{tabular}{lrrrr}
\hline & \multicolumn{2}{c}{ Maori } & \multicolumn{2}{c}{ Non-Maori } \\
Industry & 1986 & 1996 & 1986 & 1996 \\
\hline Agriculture & 13.1 & 13.3 & 12.3 & 11.8 \\
Apparel & 1.7 & 1.0 & 1.6 & 1.3 \\
Basic Metal & 0.7 & 0.7 & 0.7 & 0.6 \\
Bus.Fin.Services & 2.5 & 6.2 & 7.3 & 12.0 \\
Chemical & 1.8 & 1.5 & 2.2 & 1.6 \\
Comm.Pers. & 15.7 & 17.7 & 17.3 & 17.3 \\
Services & & & & \\
Construction & 13.6 & 11.3 & 10.3 & 10.0 \\
Electricity & 2.1 & 0.8 & 1.5 & 0.8 \\
Food & 11.6 & 8.3 & 5.8 & 4.2 \\
Machinery & 7.0 & 5.7 & 8.1 & 6.3 \\
Mineral & 1.4 & 1.0 & 0.9 & 0.6 \\
Mining & 1.0 & 0.6 & 0.6 & 0.5 \\
Other Manuf. & 0.2 & 0.3 & 0.3 & 0.4 \\
Paper\&Printing & 2.3 & 1.7 & 2.6 & 2.2 \\
Trade/Restaurants & 11.2 & 18.0 & 17.1 & 21.3 \\
Transport & 10.2 & 8.0 & 8.9 & 6.9 \\
Wood & 3.8 & 3.8 & 2.6 & 2.3 \\
\hline & & & & \\
\hline & 100.0 & 100.0 & 100.0 & 100.0 \\
\hline
\end{tabular}

\section{Conclusions}

Using Census data for 1986 to 1996 I have shown that Maori/non-Maori differences in employment and unemployment rates increased over the ten-year period. In search for a possible explanation, multinomial logit models were estimated in order to control for changes in socio-economic and demographic factors such as age, qualification and family and parental situation. The analysis has shown that Maori/non-Maori differences in employment were only partially explained by the model. It was hypothesised that increasing returns to skills and changes in the sectoral composition of the workforce both contributed to the observed development.

One of the initial motivations of this research was to establish how Maori labour market outcomes might have been affected by the ECA. In the absence of a controlled experiment, the evidence is indirect and has to be treated with caution. If one shares the opinion that the ECA might have facilitated a more market oriented remuneration of work, and thus contributed to increased returns to skills, and moreover reduced the cost of employment adjustments that were triggered by changes in technology, globalisation, or changes in demand, then the ECA might have had indeed an indirect adverse effect of Maori labour market outcomes, at least in the short run.

\section{Future research}

Maori/non-Maori disparities in labour market outcomes are likely to remain a challenge for public policy and academic research for quite some time. Many important aspects have not been addressed in this paper. For instance, Chapple and Rea (1999) expose in some detail the problems associated with defining ethnicity and dealing with multiple ethnicity responses. The fact that education and family decisions are likely to be determined jointly with (rather than exogenously of) labour market outcomes is also ignored, here, as well as in most of the previous literature on the determinants of employment. The formulation of a more elaborate structural model might pay great dividends for understanding the ultimate sources of Maori/non-Maori disparities.

\section{Notes}

1 "Relative" outcomes in employment and unemployment rates are defined here in terms of percentage point differences rather than percentage differences, i.e., by taking difference rather than ratios of rates.

2 Note that this definition of employment counts full-time and part-time employment on a one-to-one basis and thus differs from the concept of "full-time equivalent" employment.

3 The original multinomial model provides separate results for each of the four labour market states. For the sake of simplicity, I have aggregated full-time and parttime employment into one single category.

4 It is well known from the literature on estimating returns to schooling in earnings functions that this statement is admissable only under the very restrictive assumption that schooling choices are exogenous. The emerging consensus appears to be that neglecting endogeneity probably causes the estimates to be downward biased (Card, 1998).

5 The industry classification used here combines information from the 2-digit and 3-digit NZSIC classification. A concordance is available from the author on request.

6 This decrease is a general feature of Census data and not restricted to the sub-sample used here. Published data from the Household Labour Force Survey, however, show an increase in male employment between 1986 and 1996. One possible explanation for the discrepancy is the increasing number of "dummies" in the Census, non-respondent persons for whom little else than their existence is known to Statistics New Zealand (an estimated 40,000 working-age men in 1996). Published employment statistics simply exclude these observations without further adjustment. Note that the use of full-time equivalent employment would lead to an even larger fall in Census employment, as the proportion of part-time workers was much higher in 1996 than in 1986.

\section{References}

Card, D. (1998) The causal effect of education on earnings, in O. Ashenfelter and D. Card (eds) Handbook in Labor Economics, Volume 3, Amsterdam (North-Holland). 
Chapple, S. and Rea, D. (1999) Disparity between Maori and non-Maori labour market outcomes in the Household Labour Force Survey, in P.S. Morrison (ed.) Proceedings of the Eighth Conference, Labour Employment and Work in New Zealand. Victoria University Wellington.: 25-30

Easton, B. (1994) The Maori in the labour force. Report prepared for Te Puni Kokiri.

Easton, B. (1995) The Maori in the labour force. In: P.S. Morrison (ed.) Labour Employment and Work in New Zealand. Proceedings of the Sixth Conference November 24 \& 251994 Victoria University Wellington, 206-213.

Evans, L., Grimes, A. and Wilkinson, B. (1996) Economic Reform in New Zealand 1984-1995: The Pursuit of Efficiency, Joumal of Economic Literature $34,1856-1902$.

Haines, L. (1989) Work Today: Employment Trends to 1989. Wellington: New Zealand Planning Council.

Harbridge, R (1993) Bargaining and the Employment Contracts Act: an overview, in: R. Harbridge (ed.) Employment Contracts: New Zealand Experiences, Victoria University Press, Wellington.

Maloney, T. (1997) Has New Zealand's Employment Contracts Act increased employment and reduced wages?, Australian Economic Papers 36, 243-264.

Oaxaca, R. (1978) Male-Female Wage Differentials in Urban Labor Markets, International Economic Review 14, 693-709.

Winkelmann, L. and Winkelmann, R. (1997) Determining the Relative Labour Force Status of Maori and non-Maori using a Multinomial Logit Model, Labour Market Bulletin 1, 24-62.

\title{
Acknowledgements
}

The data were accessed through Statistics New Zealand's Data Laboratory, and the support of Robert Didham, Sandra MacDonald, and Richard Penny is gratefully acknowledged. The paper was completed while I enjoyed the hospitality of the Institute for the Study of Labour (IZA), Bonn, in November 1998. I benefited from comments by Simon Chapple, Sylvia Dixon, Kerry Papps and Liliana Winkelmann.

\author{
Author \\ Rainer Winkelmann is a Senior Lecturer, \\ Department of Economics, \\ University of Canterbury, \\ PO Box 4800, \\ Christchurch. \\ E-mail: R.Winkelmann @econ.canterbury.ac.nz
}

